$$
\begin{aligned}
& \text { SAND--97-1180C } \\
& \text { SANO97.1180 } \\
& \text { CONF-970953-- }
\end{aligned}
$$

\title{
SILICON-PHOTODIODE PYRANOMETERS: OPERATIONAL CHARACTERISTICS, HISTORICAL EXPERIENCES, AND NEW CALIBRATION PROCEDURES
}

\author{
David L. King, Sandia National Laboratories, Albuquerque, NM, 87185 \\ Daryl R. Myers, National Renewable Energy Laboratory, Golden, CO, 80401
}

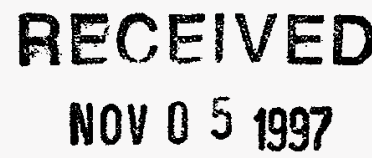

\begin{abstract}
Small, low-cost, silicon-photodiode pyranometers are now widely used for solar irradiance measurements associated with solar thermal and photovoltaic power systems, as well as for agricultural applications. Without correction, the irradiance values indicated by these pyranometers may differ from the "true" broadband solar irradiance by over $10 \%$. This paper identifies the time-ofday dependent factors responsible for these systematic errors, and describes new procedures that effectively compensate for the systematic influences. Application of the procedures should improve calibration methods and the accuracy of field measurements.
\end{abstract}

\section{INTRODUCTION}

The National Renewable Energy Laboratory (NREL) in collaborative efforts with the Department of Commerce, National Oceanic and Atmospheric Administration Solar Radiation Facility (NOAA/SRF) at Boulder, $\mathrm{CO}$, has for many years calibrated all types of solar pyranometers [1]. Since 1978, Sandia National Laboratories (SNL) has been calibrating a large group of pyranometers in support of their photovoltaic systems engineering activities. The collective experience at both laboratories has now been integrated as part of the National Center for Photovoltaics (NCPV). A collaborative effort has resulted providing a better understanding of the characteristics of siliconphotodiode pyranometers.

Silicon-photodiode irradiance pyranometers were developed as a low cost alternative to thermopile-based pyranometers to provide integrated solar resource information for climatological research [2]. One manufacturer has now produced over 27,000 of the devices [3]. However, the variability observed in calibration data for silicon-photodiode pyranometers has previously led metrologists to the conclusion that instantaneous solar irradiance measurements with these devices have an uncertainty at least twice as large as those from thermopile-based pyranometers [4]. Two examples will be given to illustrate the variability.. Over a one year period, month-to-month (seasonal) variations of about $5 \%$ were observed in the apparent calibration factor for a silicon-based pyranometer, Fig. 1.

Sandia is a multiprogram laboratory operated by Sandia Corporation, a Lockheed Martin Company, for the United States Department of Energy under Contract DE-ACO494AL85000.
During calibration over a single day, ent variations have been observed in apparent calibration factor for a tilted versus horizontal orientation of a silicon pyranometer, Fig. 2. Other authors have documented similar experience and their attempts to correct the measurements from these pyranometers $[5,6,7]$.

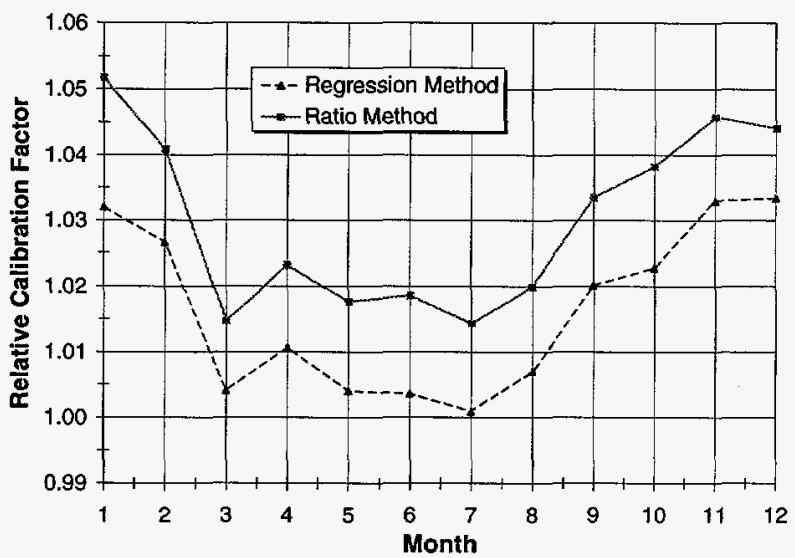

Fig.1. Variation in relative calibration factor of a siliconphotodiode pyranometer by month using two different NOAA/NREL calibration methods.

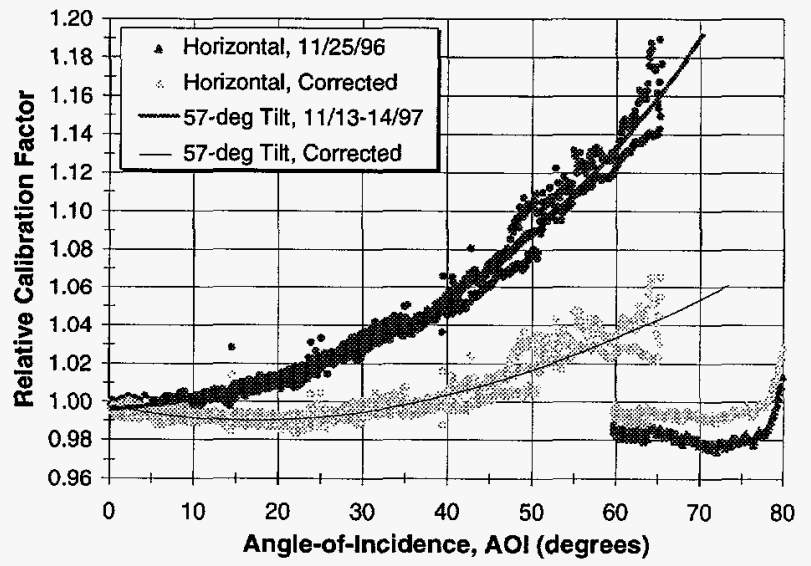

Fig. 2. Relative calibration factor for silicon-photodiode pyranometer versus solar angle-of-incidence during NREL calibration. "Corrected" data uses procedures from this work to compensate for spectral and $\mathrm{AOI}$ influences. 


\section{DISCLAMMIER}

Portions of this document may be illegible in electronic image products. Images are produced from the best available original document. 


\section{DISCLAIMER}

This report was prepared as an account of work sponsored by an agency of the United States Government. Neither the United States Government nor any agency thereof, nor any of their employees, makes any warranty, express or implied, or assumes any legal liability or responsibility for the accuracy, completeness, or usefulness of any information, apparatus, product, or process disclosed, or represents that its use would not infringe privately owned rights. Reference herein to any specific commercial product, process, or service by trade name, trademark, manufacturer, or otherwise does not necessarily constitute or imply its endorsement, recommendation, or favoring by the United States Government or any agency thereof. The views and opinions of authors expressed herein do not necessarily state or reflect those of the United States Government or any agency thereof. 
It is important to realize that the calibration procedures now applied to silicon-photodiode pyranometers $[8,9,10]$ are methods historically developed for thermopile-based pyranometers, and may not be directly applicable to silicon pyranometers. Work recently conducted at SNL clarifies the systematic influences observed in measurements with silicon-photodiode pyranometers, and will lead to improved calibration methods and field accuracy for these devices.

\section{FACTORS INFLUENCING RESPONSE}

When used for solar irradiance measurements, pyranometers can be influenced by a variety of extraneous factors. These factors may include solar angle-of-incidence (AOI), device temperature, tilt orientation of the pyranometer, mechanical and optical asymmetries in the instrument, thermal response time, the ratio of the diffuse to direct components of the total irradiance, linearity of response with irradiance level, and the path across the pyranometer that the sunlight traverses. For silicon-photodiode pyranometers, the influence of the solar spectrum and the calibration of associated shunt resistors must be added to this list of factors, but thermal response time can be ignored.

Fig. 3 illustrates the spectral response of a typical LICOR LI-200 silicon-photodiode pyranometer relative to the solar spectrum at different times of the day. For solar spectra at sunrise or sunset with a higher percentage of long wavelength irradiance, the response of a siliconphotodiode pyranometer can be expected to increase relative to the "bluer" spectrum at solar noon.

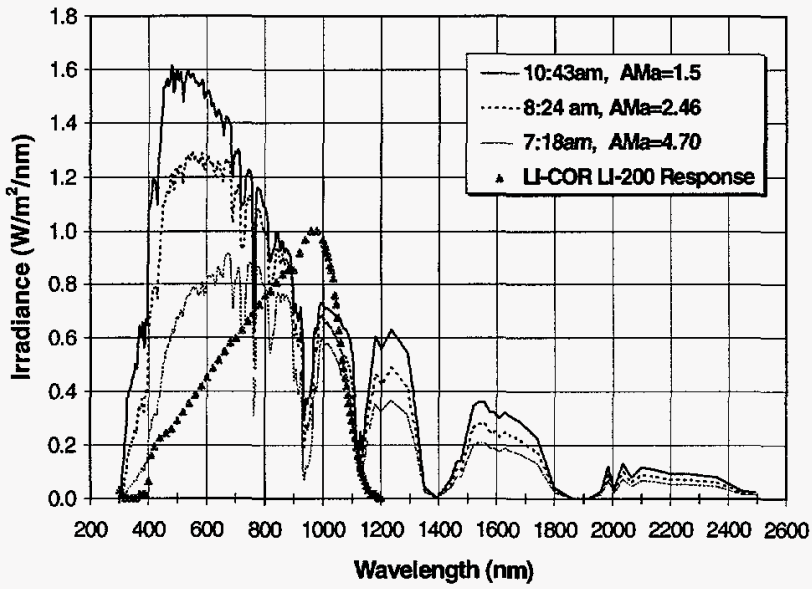

Fig. 3. Normalized spectral response of LI-COR siliconphotodiode pyranometer compared to global solar irradiance at different times of day.

\section{NEW RESPONSE MODEL}

The analytical model describing the output or response, $R$, of silicon-photodiode pyranometers is given by Eqn. 1. The model separates the response of the pyranometer into two components ( $E_{\text {dni }}$ and $E_{\text {diff }}$ ), one related to the direct normal component of solar irradiance and the other to the diffuse component. Note that this model resulted in different calibration constants $\left(\mathrm{C}_{1}, \mathrm{C}_{2}\right)$ for direct versus diffuse solar irradiance, and that both are referenced to a common irradiance level, $E_{0}$, typically $1000 \mathrm{~W} / \mathrm{m}^{2}$.

The pyranometer's response to the direct irradiance component is influenced by the cosine of the solar angleof-incidence, $\mathrm{AOI}$, and by the optical characteristics of its diffuser. The procedure for calculating $\mathrm{AOI}$ is documented elsewhere [11]. The optical characteristics of the diffuser were described by an empirically determined function, $f_{2}(\mathrm{AOI})$, called the "AOI Function." The response of the pyranometer to the diffuse irradiance was assumed to have no dependence on angle-of-incidence.

The influence of the continuously changing solar spectrum was included in the model as an empirically determined function, $f_{1}\left(A M_{a}\right)$, called the "AMa Function" related to the absolute air mass $\left(A M_{a}\right) . A M_{a}$ is the term used to describe the path length that sunlight traverses through the atmosphere before reaching the ground, with adjustment made for the altitude of the site. $A M_{a}$ is readily calculated knowing time of day and site latitude, longitude, and altitude [11].

The influence of temperature, $\mathrm{T}$, on a pyranometer's response was compensated for by using a temperature coefficient, $\alpha$, determined in the same manner routinely used for photovoltaic reference cells [12]. The reference temperature, $\mathrm{T}_{0}$, was assumed to be $25^{\circ} \mathrm{C}$. Temperature coefficients measured for seven different LI-COR pyranometers gave an average value of $+0.00082\left(1 /{ }^{\circ} \mathrm{C}\right)$ with a standard deviation of \pm 0.00021 .

$$
\begin{aligned}
& R=f_{1}\left(A M_{a}\right) \cdot\left[C_{1} \cdot \frac{E_{d n i}}{E_{o}} \cdot \cos (A O I) \cdot f_{2}(A O I)\right. \\
& \left.+C_{2} \cdot \frac{E_{\text {diff }}}{E_{o}}\right] \cdot\left[1-\alpha \cdot\left(T-T_{o}\right)\right]^{-1}
\end{aligned}
$$

This model and the experimental measurement of the $\mathrm{AM}_{\mathrm{a}}$ and $\mathrm{AOI}$ Functions have led to a technique for making first order corrections to irradiance measurements using silicon-photodiode pyranometers. The technique can also be applied to photovoltaic reference cells or any other solar irradiance sensor that is based on a photovoltaic device. The distinction of the new technique is its method for separating the effects of solar spectrum, angle-of-incidence, and temperature. The technique is thoroughly documented elsewhere [13].

\section{Measuring the $\mathrm{AM}_{\mathrm{a}}$ Function}

The concept of the $A M_{2}$ Function can be understood by examining the standard ASTM formulation for calculating a "spectral mismatch correction" [14]. The spectral mismatch correction is used to correct the shortcircuit current $\left(I_{\mathrm{sc}}\right)$ measured under a test spectral irradiance to the value expected under a reference solar spectral irradiance. Two solar spectra have been standardized as references by ASTM for the $A_{a}=1.5$ condition, one for the direct normal spectrum and one for the global spectrum $[15,16]$. The outdoor test method for 
measuring the $\mathrm{AM}_{\mathrm{a}}$ Function is straightforward and basically applies the concept of spectral mismatch correction on a continuous basis over the day. The test method is documented elsewhere [11].

Fig. 4 shows the $\mathrm{AM}_{\mathrm{a}}$ Functions measured on three different dates for a typical LI-COR LI-200 siliconphotodiode pyranometer under clear sky test conditions in Albuquerque, NM. Note that the solar spectral influence results in systematic impact on the relative response of the instrument; a $2 \%$ effect from $\mathrm{AM}_{a}=1$ to 1.5 and an $8 \%$ effect from $A M_{a}=1.5$ to 5 . Our experience has been that the spectral response of the photodiodes used in the LICOR devices has been consistently the same for many years, and consequently the $\mathrm{AM}_{\mathrm{a}}$ Functions are repeatable from one instrument to the next. Thus, the polynomial fit in Fig. 4 is offered as a generic spectral correction for LI-COR pyranometers, when used under clear sky test conditions. Please recognize that the results shown in Fig. 4 are only applicable to LI-COR pyranometers; the $\mathrm{AM}_{\mathrm{a}}$ Functions for other photovoltaic devices can be significantly different and must be measured separately [11].

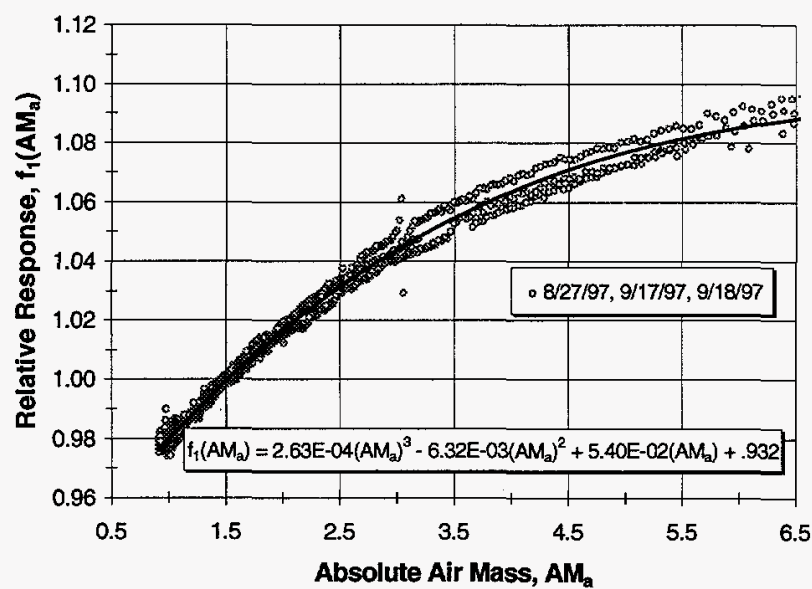

Fig. 4. $A M_{a}$ Function for several LI-COR siliconphotodiode pyranometers for clear sky test conditions.

\section{Measuring the AOI Function}

The outdoor test method for measuring the AOI Function has also been documented elsewhere [11]. Basically the procedure involved mounting the pyranometer on a computer-controlled solar tracker and then moving the tracker through a programmed sequence of azimuth offset angles resulting in the $\mathrm{AOI}$ being varied from -90 to +90 degrees; while maintaining other variables such as irradiance level, solar spectrum, and ambient temperature nominally constant. Fig. 5 shows the measured influence of $\mathrm{AOI}$ on the pyranometer's response. The measured result is consistent with the manufacturer's specification and with indoor measurements by other researchers [17]. The influence of $\mathrm{AOI}$ was also found to be similar from one LI-COR device to the next, thus the polynomial fit in Fig. 5 can be used as a generic correction. The results shown in Fig. 5 are only applicable to LI-COR pyranometers.

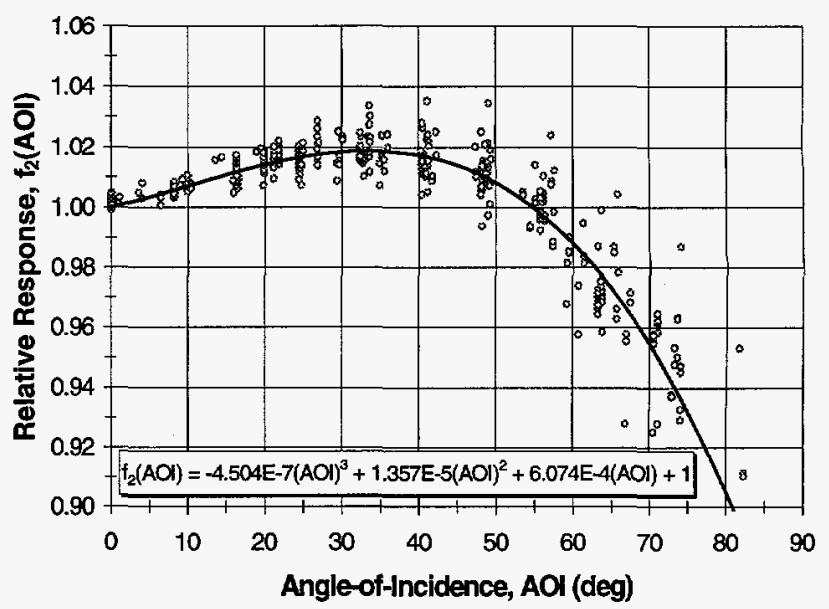

Fig. 5. Relative response of LI-COR LI-200 pyranometers versus solar angle-ot-incidence.

\section{CALIBRATION METHODS}

Silicon-photodiode pyranometers are fundamentally photovoltaic devices, and as such, standard ASTM test procedures can be applied to calibrate them by using a solar simulator $[18,19]$. In this manner, it is possible to obtain calibration constants $\left(C_{1}, C_{2}\right)$ for both the ASTM standard direct normal spectrum [15] and for a diffuse solar spectrum, as required by the model in Eqn. 1. In lieu of an ASTM standard for the "blue rich" diffuse solar spectrum, a reasonable approximation, consistent with measured diffuse spectra [11], can be calculated as the difference between the standard ASTM global and direct normal spectra. Then the spectral mismatch correction procedure [14] can be used to determine the calibration constant for a diffuse spectrum, $\mathrm{C}_{2}$. Using this approach, we calculated that $\mathrm{C}_{2}$ for a diffuse spectrum was $7.3 \%$ lower than the calibration constant for the ASTM standard direct normal spectrum.

Conventional outdoor calibration procedures [8, 9] can also be applied to for these silicon-photodiode pyranometers, as long as the $\mathrm{AM}_{\mathrm{a}}$ and $\mathrm{AOI}$ Functions are used to compensate for spectral and angle-of-incidence influences. For instance, the "corrected" calibration factor previously shown in Fig. 2 was obtained by applying the generic $\mathrm{AM}_{\mathrm{a}}$ and $\mathrm{AOl}$ corrections given in this paper to calibration data obtained by NREL using traditional methods. For both the tilted and horizontal orientation, these corrections gave calibration values that varied by less than $\pm 2 \%$, for test conditions with $\mathrm{AM}_{\mathrm{a}}<3.5$.

\section{APPLICATION OF CORRECTIONS}

Eqn. 2 gives a general expression for correcting the measured response, $R$, from a silicon-photodiode pyranometer for the influences of solar spectrum, angleof-incidence, and temperature. Using the corrected response, an improved estimate for the total (broadband) irradiance, $E_{t}$, can be obtained. In this general case, an estimate of an additional parameter, $k=$ the ratio of the 
diffuse to total irradiance, is needed. However, depending on how much information is available to the user, Eqn. 2 lends itself to simplification. For instance, if temperature correction is not employed, then the temperature related factor in square brackets can be deleted. If no attempt is made to distinguish between the direct and diffuse solar components, then the divisor can be deleted and a single calibration constant used. in all cases, $\mathrm{AM}_{\mathrm{a}}$ and $\mathrm{AOI}$ corrections given in Figs. 4 and 5 should be applied.

$E_{t}=\left\{\frac{R \cdot E_{0} \cdot\left[1-\alpha \cdot\left(T-T_{0}\right)\right]}{C_{1} \cdot f_{1}(A M a) \cdot f_{2}(A O I)}\right\} \cdot\left\{1+k \cdot\left[\frac{C_{2}}{C_{1} \cdot f_{2}(A O I)}-1\right]\right\}^{-1}$

To further illustrate the effectiveness of the relationship defined by Eqn. 2, a comparison between total irradiance measurements using an Eppley PSP pyranometer and a corrected LI-COR pyranometer are shown in Fig. 6. The data shown in Fig. 6 were recorded on several different days (clear sky and overcast) with both the Eppley PSP and the LI-COR on a solar tracker, eliminating $\mathrm{AOI}$ influences. Corrections were applied for $\mathrm{AM}_{\mathrm{a}}$ and temperature, and a single calibration constant was used (no distinction between $E_{\text {dni }}$ and $E_{\text {diff }}$ ). For the days shown, the $A M_{a}$ range was from 1 to 10 . On clear days, the agreement between the LI-COR and PSP was remarkably good, with differences less than $\pm 1 \%$. In contrast, without corrections on clear days LI-COR measurements were 10\% high at low irradiance and 3\% low at high irradiance. For cloudy conditions, the corrected data agreed within $\pm 5 \%$; but without corrections differences ranged from $15 \%$ high to $10 \%$ low.

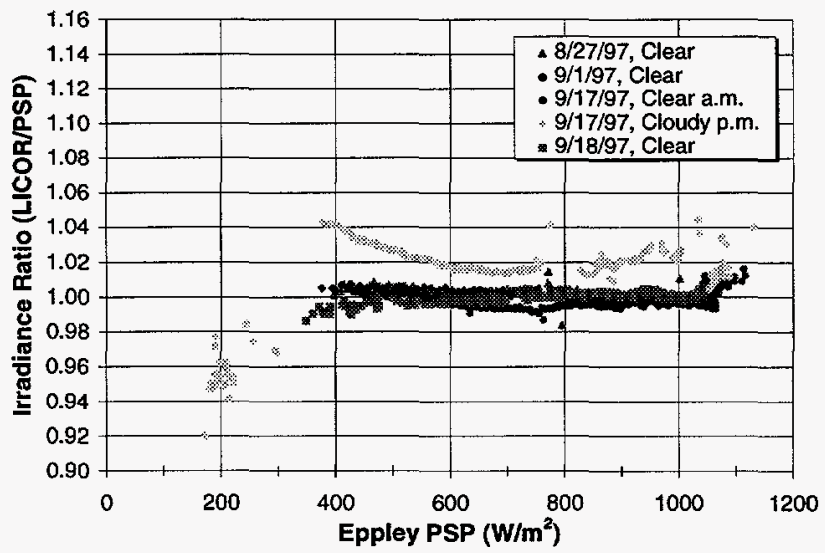

Fig. 6. Ratio of corrected LI-COR to Eppley PSP irradiance measurements, clear and cloudy conditions.

\section{CONCLUSIONS}

This work has provided strong evidence that by addressing the systematic influences associated with solar spectrum, solar angle-of-incidence, and temperature, the accuracy of total irradiance measurements using silicon-photodiode pyranometers can be comparable to that achieved using thermopilebased pyranometers. Additional field experience for a wider variety of operating conditions and sites are needed to firmly establish the general applicability of the generic corrections provided in this paper. The procedures documented in this paper are also applicable to photovoltaic reference cells and modules.

\section{ACKNOWLEDGEMENTS}

The authors would like to thank the following people for their review of this work: Bill Boyson and Phil Thacher (Sandia), Ted Cannon (NREL), John Wurm (LI-COR), Joe Michalsky (SUNY), Gene Zerlaut (SC-International), Bob Hammond (ASU), and Andy Rosenthal (SWTDI/NMSU).

\section{REFERENCES}

[1]. D. R. Myers, "Radiometric Instrumentation and Measurements Guide for Photovoltaic Testing," NRELITP. 560-21774, April 1997.

[2]. J. P. Kerr, et. al., "An Integrating Pyranometer for Climatological Observer Stations and Metoscale Networks," Applied Metrology, (6), 1967, pp.688-694.

[3]. "LI-COR Terrestrial Radiation Sensors, Instruction Manual," Publication No. 8609-60, LI-COR Inc., 1986.

[4]. D. R. Myers, et. al., "Uncertainty Estimates for Global Solar Irradiance Measurements Used to Evaluate Photovoltaic Device Performance," Solar Cells, (27). 1989 , pp.455-464.

[5]. J. J. Michalsky, et. al., "Spectral and Temperature Correction for Silicon Photovoltaic Solar Radiation Sensors," Solar Energy, (47), 1991, pp.299-305.

[6]. C. Zhou and J. Michalsky, "Spectral Correction of Silicon Photodiode Solar Radiation Detectors," American Solar Energy Society, 1992, pp.335-339.

[7]. M. S. Imamura, et. al., "Assessment of Simplified Outdoor Calibration Methods for Silicon Solar Irradiance Sensors," $11^{\text {th }}$ European PV Energy Conference, 1992.

[8]. ASTM E 941, "Calibration of Reference Pyranometers With Axis Tilted by the Shading Method."

[9 ASTM E 913, "Calibration of Reference Pyranometers With Axis Vertical by the Shading Method."

[10]. ASTM E 824, "Transfer of Calibration from Reference to Field Pyranometers."

[11]. D. L. King, et. al., "Measuring Solar Spectral and Angle-of-Incidence Effects on PV Modules and Solar Irradiance Sensors," this conference.

[12]. ASTM E 1125, "Calibration of Primary Terrestrial PV Reference Cells Using a Tabular Spectrum."

[13] D. King, et. al., "LI-COR LI-200 Silicon-Photodiode Pyranometers: Operational Characteristics and Improved Calibration Procedures," Sandia Report, to be published.

[14]. ASTM E 973, "Determination of the Spectral Mismatch Parameter Between a Photovoltaic Device and a Photovoltaic Reference Cell."

[15]. ASTM E 891, "Terrestrial Direct Normal Solar Spectral Irradiance for Air Mass 1.5."

[16]. ASTM E 892, "Terrestrial Solar Spectral Irradiance at Air Mass 1.5 for a $37^{\circ}$ Tilted Surface."

[17]. J. J. Michalsky, et. al., "Cosine Response Characteristics of Radiometric and PV Sensors," American Solar Energy Society, 1992, pp.335-339.

[18]. ASTM E 948, "Electrical Performance of NonConcentrator Terrestrial PV Cells Using Reference Cells." [19]. ASTM E 1125, "Calibration of Primary NonConcentrator Terrestrial Photovoltaic Reference Cells Using a Tabular Spectrum." 